\title{
DNA restriction fragment length polymorphism differentiates recurrence from relapse in treatment failures of Streptococcus pyogenes pharyngitis
}

\author{
E. BINGEN, E. DENAMUR*, N. LAMBERT-ZECHOVSKY, N. BRAIMI, M. EL LAKANY and J. ELION*
}

Laboratoire de Bactériologie and "Laboratoire de Biochimie Génétique, Hôpital Robert Debré, 48 Bd Sérurier, 75019 Paris, France

\begin{abstract}
Summary. In the evaluation of treatment failure in Streptococcus pyogenes pharyngitis it is necessary to distinguish between persistence of the original streptococcus and acquisition of a new strain. We used the analysis of restriction fragment length polymorphism (RFLP) of total DNA and of ribosomal DNA (rDNA) regions (ribotypes) as epidemiological tools to compare 43 pre- and post-treatment $S$. pyogenes strains obtained from 20 patients. In 16 cases pre- and post-treatment strains gave indistinguishable RFLP patterns of total DNA, strongly suggesting relapse with the same strain. However, in four cases different patterns were obtained for the pre- and post-treatment isolates, indicating recurrence due to the acquisition of a new strain. Ribotyping did not improve discrimination among strains. Thus, analysis of DNA RFLP is a promising method for distinguishing recurrence from relapse in failures of pharyngitis treatment.
\end{abstract}

\section{Introduction}

Studies of the efficacy of antibiotic treatment of group A streptococcal pharyngitis have used streptococcal eradication rates as a measure of success. When treatment fails, it is necessary to distinguish between relapse with the persistence of the original strain of streptococcus and recurrence due to the acquisition of a new strain. ${ }^{1}$ In this study, the analysis of restriction fragment length polymorphism (RFLP) of total DNA and of ribosomal DNA (rDNA) regions (ribotyping) was used as an epidemiological tool to compare preand post-treatment $S$. pyogenes strains obtained from patients with pharyngitis who were thought to be treatment failures.

\section{Materials and methods}

\section{Patients and clinical specimens}

During the winter and spring of 1990-1991, 240 patients with clinical findings suggestive of acute pharyngitis were seen by private paediatricians in Paris, Brittany and Lorraine (France). After giving informed consent, they were enrolled in a double blind randomised multicentre study comparing treatment with penicillin V, and cefotiam hexetil. Complete results of this study will be published elsewhere. Throat cultures were obtained by rubbing a sterile, rayontipped swab over the posterior portion of the pharynx

Received 14 Oct. 1991; revised version accepted 18 Nov. 1991. and over both tonsils (or tonsillar fossae). The swab was immediately streaked on a blood agar plate (Trypticase Soy Agar with sheep blood 5\%; Diagnostic Pasteur, Marnes-la-Coquette, France). The plate was examined for the presence of $\beta$-haemolytic streptococci after overnight anaerobic incubation at $37^{\circ} \mathrm{C}$. All patients were asked to return for two followup visits, 10 and 30 days after the start of antibiotic therapy. At each follow-up visit, a further throat culture was obtained. Patients presenting with persistent symptoms and with both pre- and posttreatment cultures positive for $S$. pyogenes, were selected for this study.

\section{Bacterial strains}

All $\beta$-haemolytic streptococcal strains were grouped with the Streptex test (Wellcome Diagnostics, Dartford, Kent). S. pyogenes isolates were stored in ToddHewitt broth at $-70^{\circ} \mathrm{C}$.

\section{RFLP analysis}

Total $S$. pyogenes DNA was prepared as previously described $;^{2} 4 \mu \mathrm{g}$ of DNA was digested with HindIII and PvuII restriction enzymes (Boehringer, Mannheim, Germany) according to the manufacturer's specifications and analysed by electrophoresis on submarine, ethidium bromide-containing, agarose $0.8 \%$ gels in $1 \mathrm{~mm}$ Tris-acetate, $1 \mathrm{~mm}$ EDTA buffer. DNAfragment-size marker Raoul I (Appligene, Strasbourg, France) was used. The separated restriction fragments were transferred to a nylon membrane (Gene Screen 

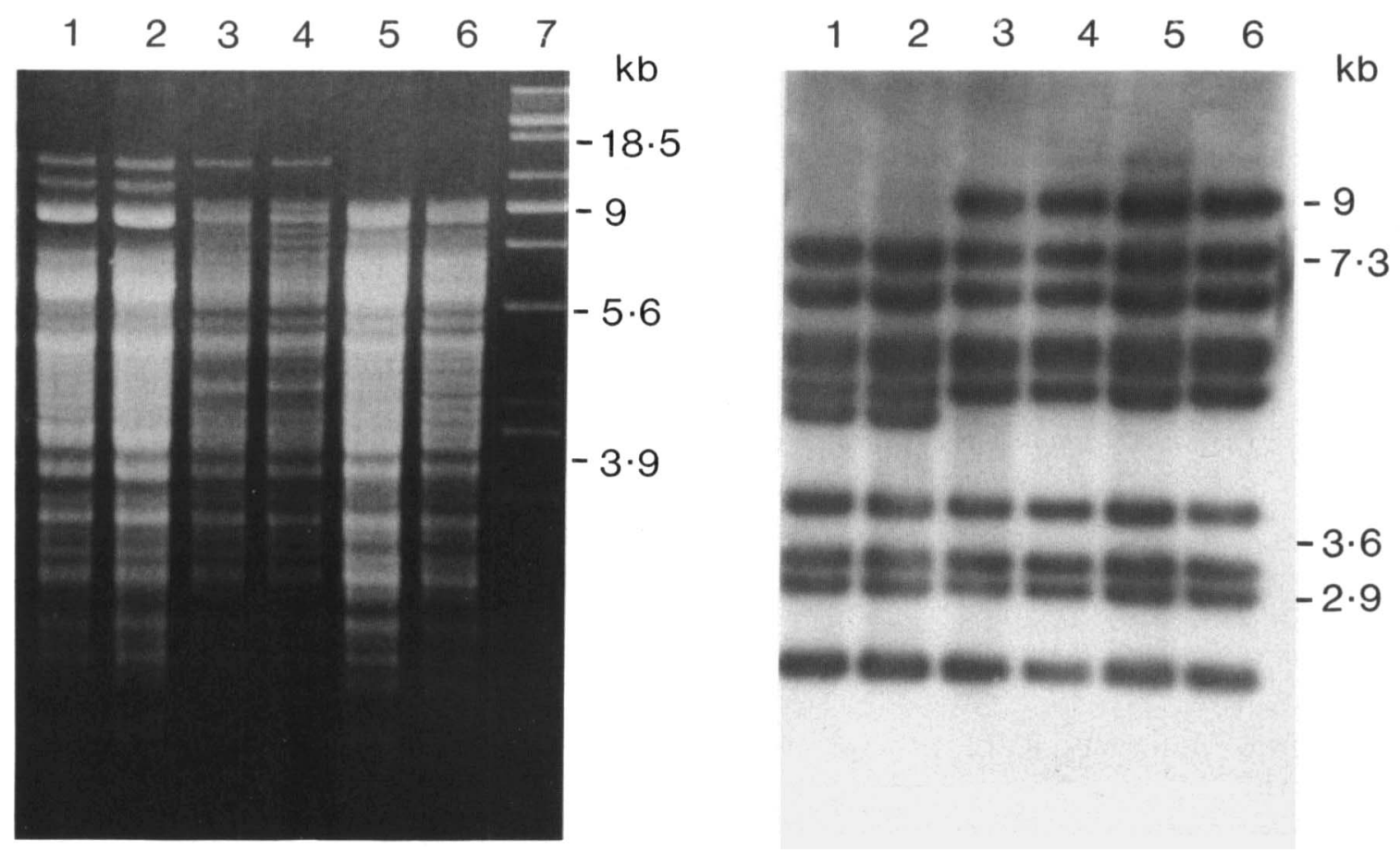

A

B

Fig. 1. Identical pre- and post-treatment $S$. pyogenes HindIII RFLP patterns: A, agarose gel after ethidium bromide staining; B, Southern blot probed with the rDNA probe. Lanes 1 and 2 , patient $1 ; 3$ and 4 , patient $2 ; 5$ and 6 , patient $3 ; 7$, size marker. Identical rDNA RFLP patterns (lanes 3-6) are obtained for strains exhibiting distinct total DNA RFLP patterns (lanes 3 and 5).

Plus, New England Nuclear Products, Boston, MA, USA) by the method of Southern. Ribosomal $16+23$ S RNA from Escherichia coli (Boehringer) was used as a probe and labelled by random oligopriming with a mixture of hexanucleotides (Pharmacia, Uppsala, Sweden) and cloned M-MLV reverse transcriptase (Bethesda Research Laboratories, Inc., Gaithersburg, MD, USA) in the presence of $0.35 \mathrm{~mm}$ DIG-11-dUTP (digoxigenin-11-deoxyuridine-5' triphosphate, Boehringer). Membrane-bound DNA was exposed to the probe DNA and allowed to hybridise overnight at $65^{\circ} \mathrm{C}$ according to the manufacturer's instructions. The final composition of the hybridisation solution was $50 \mathrm{~mm}$ Tris- $\mathrm{HCl}, \mathrm{pH} 7.5,1 \mathrm{M}$ $\mathrm{NaCl}$, SDS $1 \%$, dextran sulphate $10 \%$, blocking reagent $0.1 \%$. The filters were washed twice with a 0.15 m sodium citrate solution containing SDS 0.1\% for $15 \mathrm{~min}$ at room temperature. Chemiluminescence detection procedures were performed, as described by the manufacturer (Boehringer), by incubating the membranes in the presence of an anti-digoxigenin antibody linked to alkaline phosphatase (AP; Boehringer) and the AP substrate, 3-(2'- Spiroadamantane)-4-methoxy-4-(3"-phosphoryloxy)-phenyl-1,2dioxetane (Tropix, Bedford, MA, USA). Filters were autoradiographed by exposure to Xomat-XAR 5 films (Kodak) for $3 \mathrm{~h}$ at room temperature.

\section{Results}

A total of 20 patients with persistent pharyngitis and pre- and post-treatment throat cultures positive for $S$. pyogenes were enrolled in this study. Of the 20 patients, 10 had positive throat cultures at the first follow-up visit (10 days after beginning the antibiotic therapy), seven at the second follow-up visit (at day 30) and three at both the first and the second follow-up visits. A total of 43 strains was obtained from the 20 patients.

\section{RFLP of total DNA}

Figs. 1A and 2 show examples of HindIII digestion patterns of DNA obtained for three and two pairs of pre- and post-treatment isolates, respectively. In fig. 1A (patients 1-3), identical total DNA RFLP patterns were observed for the pre- and post-treatment strains. In contrast, fig. 2 shows that the patterns obtained with the pre- and post-treatment strains from patients 4 and 5 were clearly different.

In 16 patients, indistinguishable RFLP patterns of total DNA were obtained for the pre- and posttreatment $S$. pyogenes strains after both HindIII and PvuII digestion. In four cases, the two enzymes generated different RFLP patterns of total DNA for the two strains of each pre- and post-treatment pair.

\section{RFLP of rDNA regions (ribotyping)}

Among the 43 strains studied, ribotyping after digestion with HindIII and PvuII endonucleases distinguished six and five patterns, respectively. Combinations of the HindIII and PvuII patterns improved discrimination among strains by defining eight distinct ribotypes. However, identical ribotypes were observed among several pairs of $S$. pyogenes strains which 


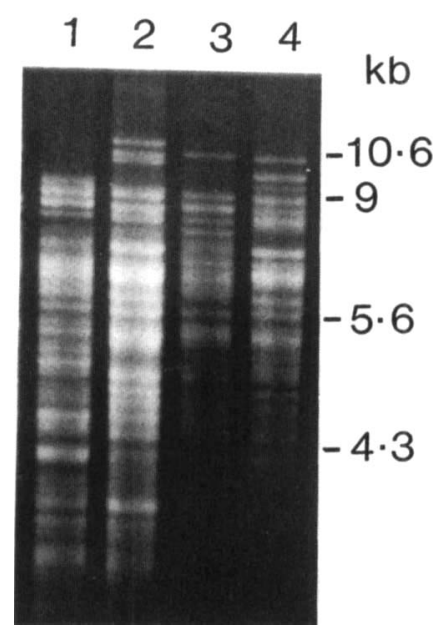

Fig. 2. Distinct pre- and post-treatment $S$. pyogenes total DNA RFLP patterns obtained after HindIII digestion. Lanes 1 and 2, patient $4 ; 3$ and 4 , patient 5 .

appeared to be distinct by RFLP patterns of total DNA (fig. 1B).

\section{Discussion}

Streptococcal pharyngitis remains a common problem in children and teenagers. Its proper management has contributed significantly to the decline of acute rheumatic fever. ${ }^{1}$ While penicillin has been the treatment of choice for four decades, an increasing incidence of clinical relapse or recurrent infection has been noted in recent years. ${ }^{3,4}$ Alternative treatment with antibiotics such as the oral cephalosporins has been evaluated in comparison with penicillins. ${ }^{5}$ Bacteriological failures have been related to $\beta$-lactamaseproducing bacteria, ${ }^{6}$ penicillin-tolerant $S$. pyogenes strains, ${ }^{7}$ inadequate antibiotic dosage $^{8}$ or chronic carriage. ${ }^{9}$ In these cases it is essential to distinguish

\section{References}

1. Dillon HC. Streptococcal pharyngitis in the 1980s. Pediatr Infect Dis $J$ 1987; 6: 123-130.

2. Bingen E, Denamur E, Lambert-Zechovsky N, Elion J. Evidence for the genetic unrelatedness of nosocomial vancomycin-resistant Enterococcus faecium strains in a pediatric hospital. J Clin Microbiol 1991; 29: 1888-1892.

3. Gastanaduy AS, Kaplan EL, Huwe BB, McKay C, Wannamaker LW. Failure of penicillin to eradicate group A streptococci during an outbreak of pharyngitis. Lancet $1980 ; 2$ : 498-502.

4. Feldman S, Bisno AL, Lott L, Dodge R, Jackson RE. Efficacy of benzathine penicillin $G$ in group $A$ streptococcal pharyngitis: reevaluation. J Pediatr 1987; 110: 783-787.

5. Pichichero ME, Margolis PA. A comparison of cephalosporins and penicillins in the treatment of group A beta-hemolytic streptococcal pharyngitis: a meta-analysis supporting the concept of microbial copathogenicity. Pediatr Infect Dis $J$ $1991 ; 10: 275-281$.

6. Brook I. The role of $\beta$-lactamase-producing bacteria in the persistence of streptococcal tonsillar infection. Rev Infect Dis $1984 ; 6$ : 601-607.

7. Kim KS, Kaplan EL. Association of penicillin tolerance with failure to eradicate group A streptococci from patients with pharyngitis. $J$ Pediatr 1985; 107: 681-684.

8. Gerber MA, Randolph MF, DeMeo K, Feder HM, Kaplan EL. Failure of once-daily penicillin $\mathrm{V}$ therapy for streptococcal pharyngitis. Am J Dis Child 1989; 143: 153-157. between relapses with homologous strains of S.pyogenes and the acquisition of new unrelated strains. ${ }^{1}$ Until now, epidemiological studies of $S$. pyogenes have been based on phenotypic studies such as serotyping, ${ }^{10}$ bacteriocin typing, ${ }^{11}$ phage typing ${ }^{12}$ and pyrolysis mass spectrometry. ${ }^{13}$ Recently, RFLP analysis of total DNA has provided an alternative method for studying the epidemiology of $S$. pyogenes isolates from various outbreaks. ${ }^{14,15}$ In the present study, we applied RFLP analysis to the evaluation of 20 cases of treatment failure in streptococcal pharyngitis. The results indicated that, in 16 cases, bacteriological failure was associated with the persistence of the original strain, but in four cases new strains were acquired. When the same strain persisted, it was detected at the first followup visit in all cases but one. Recurrence with acquisition of a distinct strain was observed at the second follow up visit in three out of seven cases.

RFLP analysis of total DNA after ethidium bromide staining is a rapid and inexpensive method and is easier to perform than serotyping. The large number of fragments obtained may be a problem when comparing large numbers of strains, but it was easy to compare pairs of strains by this method. Analysis of DNA restriction patterns has been refined by using labelled rDNA to probe the ubiquitous and polymorphic rDNA loci. ${ }^{16,17}$ However, in this study ribotyping was less discriminatory than total DNA RFLP analysis.

The analysis of RFLP of total DNA from pre- and post-treatment streptococcal isolates from pharyngitis treatment failures is a simple and effective way to distinguish recurrence from relapse and will be useful in assessing the efficiency of new antibiotic treatments.

We thank Drs Chatelain and Rio for the gift of the strains, Professor Carbon, coordinator of the clinical study, and M. Fageon for preparing the manuscript.

9. McCracken GH. Diagnosis and management of children with streptococcal pharyngitis. Pediatr Infect Dis J 1986; 5 $754-759$.

10. Lancefield RC. Serological differentiation of human and other groups of hemolytic streptococci. J Exp Med 1933; 57: 571-595.

11. Tagg JR, Bannister LV. “ Fingerprinting” $\beta$-haemolytic streptococci by their production of and sensitivity to bacteriocinlike inhibitors. J Med Microbiol 1979; 12: 397-411.

12. Skjold SA, Wannamaker LW. Method for phage typing group A type 49 streptococci. J Clin Microbiol 1976; 4: 232238.

13. Magee JT, Hindmarch JM, Burnett IA, Pease A. Epidemiological typing of Streptococcus pyogenes by pyrolysis mass spectrometry. J Med Microbiol 1989; 30: 273-278.

14. Cleary PP, Kaplan EL, Livdahl C, Skjold S. DNA fingerprints of Streptococcus pyogenes are M type specific. J Infect Dis 1988; 158: 1317-1323.

15. Bingen E, Denamur E, Lambert-Zechovsky N et al. Mother-toinfant vertical transmission and cross-colonization of Streptococcus pyogenes confirmed by DNA restriction fragment length polymorphism analysis. J Infect Dis 1992; 165: $147-150$

16. Grimont F, Grimont PAD. Ribosomal ribonucleic acid gene restriction patterns as potential taxonomic tools. Ann Inst Pasteur/Microbiol (Paris) 1986; 137B: 165-175.

17. Stull TL, LiPuma JJ, Edlind TD. A broad-spectrum probe for molecular epidemiology of bacteria: ribosomal RNA. $J$ Infect Dis 1988; 157: 280-286. 